\title{
Adsorption Properties of Ni(II) by D301R Anion Exchange Resin
}

\author{
Song Xiuling, Du Huipu, Liu Shijun, and Qian Hui \\ School of Environment Science and Engineering, Chang'an University, Xian, Shanxi 710054, China \\ Correspondence should be addressed to Song Xiuling; songxl28@sina.com
}

Received 21 October 2013; Accepted 22 December 2013; Published 4 February 2014

Academic Editor: Manuela Curcio

Copyright (C) 2014 Song Xiuling et al. This is an open access article distributed under the Creative Commons Attribution License, which permits unrestricted use, distribution, and reproduction in any medium, provided the original work is properly cited.

\begin{abstract}
The adsorption of $\mathrm{Ni}$ (II) with $\mathrm{D} 301 \mathrm{R}$ resin was investigated in this paper. The results showed that the saturated extent of adsorption $\mathrm{Ni}(\mathrm{II})$ by the resin was $84.3 \mathrm{mg} / \mathrm{g}$. The equilibrium data of $\mathrm{Ni}(\mathrm{II})$ sorption was better described by Langmuir isotherm model $\left(r^{2}=\right.$ 0.994) while that of $\mathrm{Ni}(\mathrm{II})$ sorption also fitted in Freundlich isotherm model within the experimental concentration range. The amount of the constant $\left(q_{0}\right)$ of $\mathrm{Ni}(\mathrm{II})$ under $298 \mathrm{~K}$ in Langmuir model was $76.92 \mathrm{mg} / \mathrm{g}$, which was close to the experimental results. The constant $\mathrm{n}$ was within 2-10 in Freundlich model; it was shown that adsorption of $\mathrm{Ni}$ (II) by the resin was easy to take place. The uptake kinetics followed the Lagergren pseudo-first-order rate equation $\left(r^{2}=0.9813\right)$. The particle diffusion controlled the adsorption process of $\mathrm{Ni}(\mathrm{II})$. The coefficient of the intraparticle diffusion increased with the increase of the $\mathrm{pH}$ values and the concentration of $\mathrm{Ni}(\mathrm{II})$ in aqueous solution. There was a drop of $20.1 \mathrm{~cm}^{-1}$ for the bending vibration frequency of $\mathrm{N}-\mathrm{H}$ bond. Results showed that the adsorption of $\mathrm{Ni}(\mathrm{II})$ by $\mathrm{D} 301 \mathrm{R}$ anion exchange resin was the surface complexation through the infrared spectrum analysis.
\end{abstract}

\section{Introduction}

Nickel-containing wastewater mainly comes from the smelter and electroplating factories. Excessive intake of nickel is easy to cause a variety of pathologic effects like skin allergy, lung fibrosis, and cancer $[1,2]$. Though there are very many harmful effects of nickel on human health, production of its compounds is essential and one should find the ways of reducing its input into the environment from the waste streams. Various physicochemical treatments have been developed and successfully used for the removal of heavy metals from contaminated wastewater [3-6]. A particular focus has been given to chemical precipitation, adsorption reverse osmosis, coagulation, membrane filtration, electrochemical process, and coprecipitation. Ion exchange adsorption is relatively easy to operate and possess some inherent advantages, including low cost, without secondary pollution.

Different from classical theory of ion exchange [7], the professor Wolfgang Holl put forward "surface complexation theory" to explain the adsorption behavior of the heavy metal ions on the weakly basic anion resin in recent years [8]. D301R anion exchanger resin contains slightly alkaline amino functional groups. Moving boundary models were used to study the adsorption kinetics of $\mathrm{Ni}^{2+}$ on the resin [9-12]. The infrared spectrum analysis of D301R resin was carried out before and after adsorption Ni(II). Equilibrium, kinetic data, and the infrared spectrum analysis were investigated to determine proper $\mathrm{Ni}$ (II) sorption mechanism. It was showed that the adsorption of $\mathrm{Ni}$ (II) with D301R anion exchange resin was mainly not ion-exchange adsorption mechanism but the surface complexation through the infrared spectrum analysis. The coordination bond formed between nitrogen atom on the resin and nickel ions. Theoretical and experimental basis would be provided for the application of ion exchange resin in the treatment of heavy metals in wastewater.

\section{Experimental}

2.1. Reagents and Instruments. D301R resin was purchased from Tianjin Guangfu Fine Chemical Research Institute, and the resin was reserved after swelling, pickling, alkaline washing and, water scrubbing. Nickel sulfate was of excellent grade, and other reagents used were of analytical grade. All the reagents were from China. If not specified, all the solutions used in the experiment were simulated. 
Main instruments were 752 spectrophotometer (China), DELTA-320 pH meter (Switzerland), HY-2-type multispeed oscillator, DTG160 analytical balance (China), and Tensor27 IR spectrophotometer (Bruker Company in Germany).

2.2. Determination of Adsorption Isotherm. The determination of adsorption isotherm can be carried out by the following experiment. The working solution of $200 \mathrm{~mL}$ of different concentration of $\mathrm{Ni}(\mathrm{II})$ was taken into a series of $250 \mathrm{~mL}$ conical flasks; the same suitable amount of D301R resin was added in. The $\mathrm{pH}$ of aqueous solution was measured and adjusted to the desired $\mathrm{pH}$, and each set was agitated in the shaker at the same time for 120 minutes at the same temperature. The concentration of $\mathrm{Ni}(\mathrm{II})$ in the filtrate was measured with dimethylglyoxime spectrophotometric method [13]. And the uptake capacity of $\mathrm{Ni}(\mathrm{II})$ by the resin can be calculated (1). Where $q$ is the amount adsorbed $(\mathrm{mg} / \mathrm{g})$, $C_{0}$ is the initial concentration $(\mathrm{mg} / \mathrm{L}), C_{e}$ is the equilibrium concentration (mg/L), $w$ is the mass of the resin $(\mathrm{g})$, and $V$ is the volume of aqueous solution (L),

$$
q=\frac{\left(C_{0}-C_{e}\right) \times V}{w} .
$$

2.3. Kinetic Measure. The following were the kinetic experiments. The working solution of $200 \mathrm{~mL}$ was taken into a series of $250 \mathrm{~mL}$ conical flasks, and D301R resin of $0.5 \mathrm{~g}$ was added into. The $\mathrm{pH}$ values of the solution were adjusted to the desired value. A certain volume of the supernatant was taken every 10 minutes and the concentration of $\mathrm{Ni}$ (II) was measured. Through the concentration changes of $\mathrm{Ni}$ (II) with respect to the time under the conditions of different concentrations of $\mathrm{Ni}(\mathrm{II})$ and different $\mathrm{pH}$ values of the solution,the related kinetic data was got. $F$ was calculated with (2). Where $F$ is exchange degree, $q_{m}$ is the saturated uptake capacity $(\mathrm{mg} / \mathrm{g}), C_{j}$ is the concentration of adsorption time $j(\mathrm{mg} / \mathrm{L})$, and $V_{j}$ is the volume of the solution of adsorption time $j(\mathrm{~L})$,

$$
F=\frac{C_{0} V_{0}-\left(C_{j} V_{j}+\sum_{i=1}^{j-1} C_{j} V_{j}\right)}{w q_{m}} \quad j \geq 2 .
$$

IR spectra of D301R resin samples were recorded in a Tensor27 IR spectrophotometer using $\mathrm{KBr}$ for pellet making.

\section{Results and Discussions}

3.1. The Isothermal Adsorption. Freundlich isotherm model and Langmuir isotherm model were used to describe the equilibrium state for $\mathrm{Ni}(\mathrm{II})$ adsorption experiments. The linearized forms Langmuir model and Freundlich model are given as (3).

Where $q_{0}(\mathrm{mg} / \mathrm{g})$ and $b(\mathrm{~L} / \mathrm{mg})$ are the saturated extent of sorption and the adsorption equilibrium constant in the linearized form of Langmuir isotherm model and $n$ and $K$

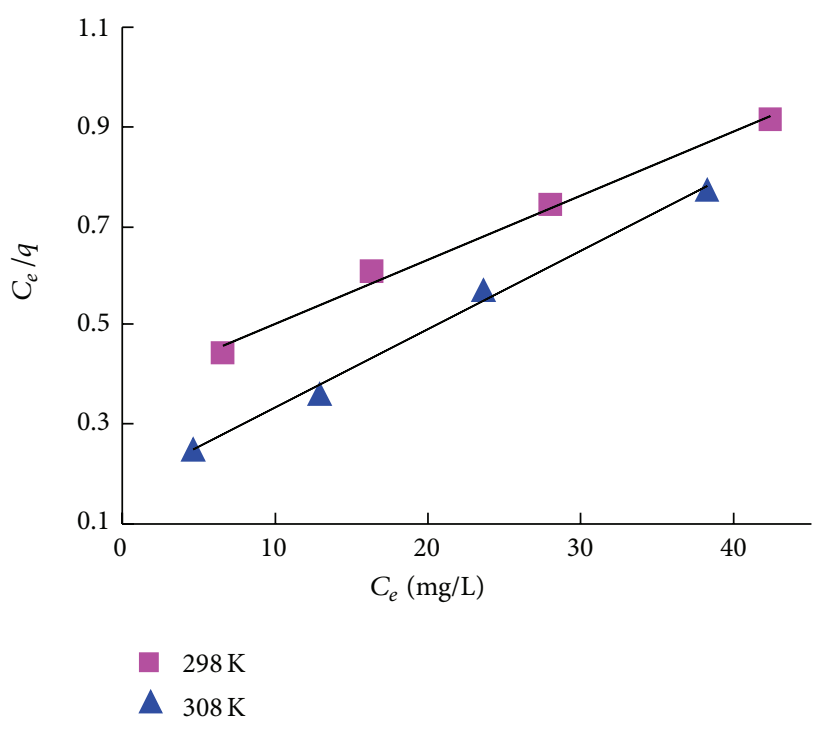

FIGURE 1: Langmuir adsorption isotherm of $\mathrm{Ni}(\mathrm{II})$ by the resin.

TABLE 1: Isotherm constants for $\mathrm{Ni}^{2+}$ adsorbed on D301R resin.

\begin{tabular}{lcccccc}
\hline \multirow{2}{*}{$T(\mathrm{~K})$} & \multicolumn{3}{c}{ Langmuir equation } & \multicolumn{3}{c}{ Freundlich equation } \\
& $q_{0}(\mathrm{mg} / \mathrm{g})$ & $b(\mathrm{~L} / \mathrm{mg})$ & $r^{2}$ & $n$ & $K$ & $r^{2}$ \\
\hline 298 & 76.92 & 0.034 & 0.994 & 4.54 & 13.59 & 0.975 \\
308 & 62.5 & 0.095 & 0.974 & 5.15 & 18.87 & 0.966 \\
\hline
\end{tabular}

are Freundlich constants incorporating all factors affecting the uptake capacity and intensity of adsorption, respectively,

$$
\begin{gathered}
\lg q=\left(\frac{1}{n}\right) \lg C_{e}+\lg K, \\
\frac{C_{e}}{q}=\left(\frac{1}{q_{0}}\right) \times C_{e}+\frac{1}{\left(q_{0} b\right)} .
\end{gathered}
$$

The Langmuir isotherms (Figure 1) assumed that there were a finite number of binding sites which were homogeneously distributed over the adsorbent surface of the cells, having the same affinity for adsorption of a single molecular layer and there was no interaction between adsorbed molecules. The Freundlich isotherms (Figure 2) assumed that the adsorption energy of a metal binding to a site on an adsorbent depended on whether or not the adjacent sites were already occupied. It was indicated that the adsorption of $\mathrm{Ni}(\mathrm{II})$ by the resin can be better described with the Langmuir model from the comparison of these two models (Table 1). The saturation uptake capacity $\left(q_{0}\right)$ of $\mathrm{Ni}(\mathrm{II})$ under $298 \mathrm{~K}$ in Langmuir model was $76.92 \mathrm{mg} / \mathrm{g}$, which was close to the experimental results. With $n$ being between 2 and 10 in the Freundlich model, it was shown that the uptake of $\mathrm{Ni}(\mathrm{II})$ by the resin was easy to take place.

\subsection{The Adsorption Kinetics}

3.2.1. The Determination of Adsorption Kinetic Model. There are two kinds of mathematical models: Lagergren pseudofirst-order kinetic model (4) and HO quasi-second-order 


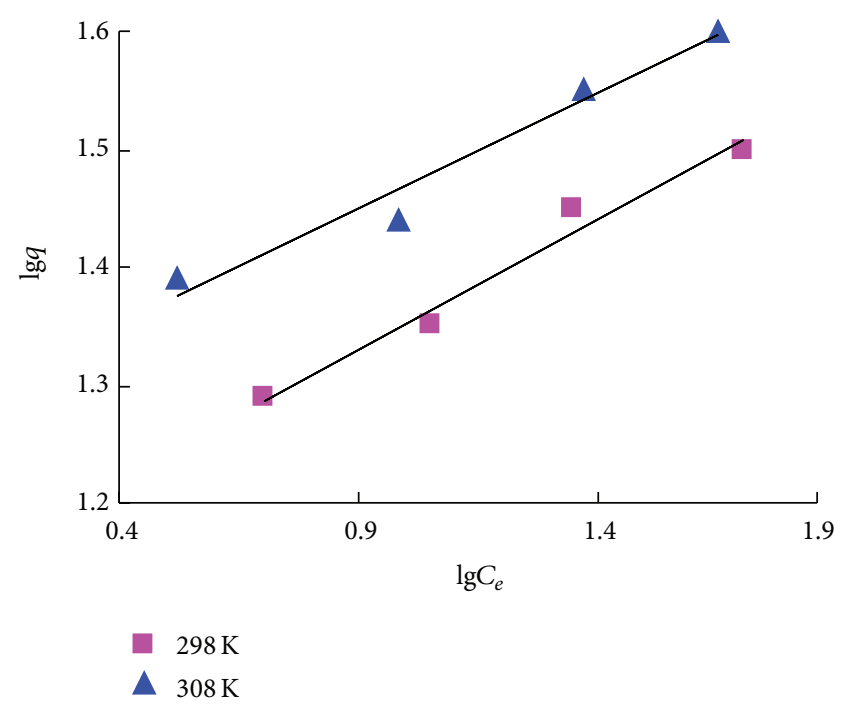

Figure 2: Freundlich adsorption isotherm of Ni(II) by the resin.

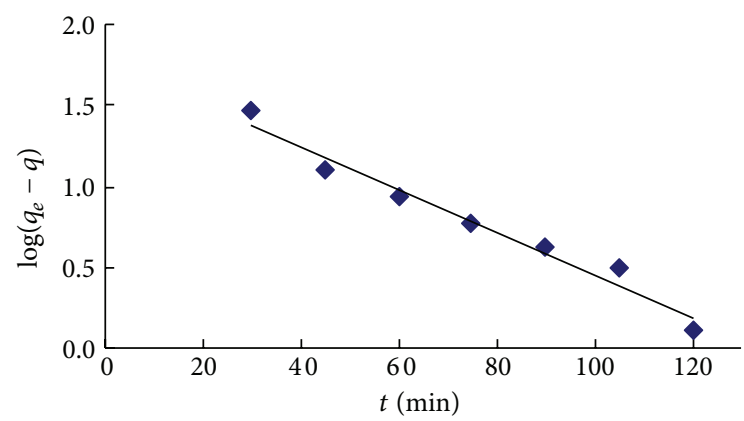

FIGURE 3: The relationship between $\log \left(q_{e}-q_{t}\right)$ and $t$.

kinetic model (5) are often used to describe the adsorption kinetics [14]

$$
\begin{gathered}
\log \left(q_{e}-q\right)=\log q_{e}-\frac{k_{1} t}{2.303}, \\
\frac{t}{q}=\frac{1}{k_{2} q_{e}^{2}}+\frac{t}{q_{t}},
\end{gathered}
$$

where $q_{t}(\mathrm{mg} / \mathrm{g})$ is the amount of adsorption time $t(\mathrm{~min})$, $q_{e}$ is the amount of adsorption equilibrium $(\mathrm{mg} / \mathrm{g}), k_{1}$ is the rate constant of the Lagergren pseudo-first-order equation $\left(\min ^{-1}\right)$, and $k_{2}$ is the rate constant of the HO secondorder equation $(\mathrm{g} / \mathrm{mg} \cdot \mathrm{min})$. Lagergren pseudo-first-order kinetic model is based on the fact that the change in $\mathrm{Ni}(\mathrm{II})$ concentration with respect to time is proportional to the power one.

In order to clarify the sorption kinetics of $\mathrm{Ni}(\mathrm{II})$ ions onto D301R resin, two kinetic models were applied to the experimental data (Figures 3 and 4). From the estimated $q$ values and $r^{2}$ values, it can be concluded that the uptake of $\mathrm{Ni}(\mathrm{II})$ in aqueous solution by D301R resin did not fit to the $\mathrm{HO}$ second-order rate equation but fitted well to the firstorder kinetic model (Table 2).

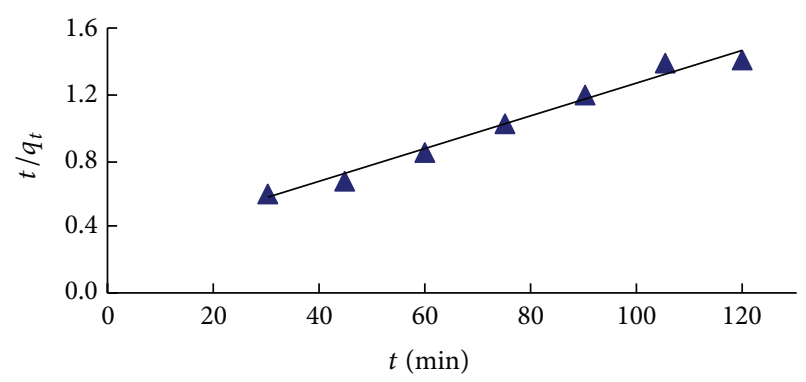

Figure 4: The relationship between $t / q_{t}$ and $t$.

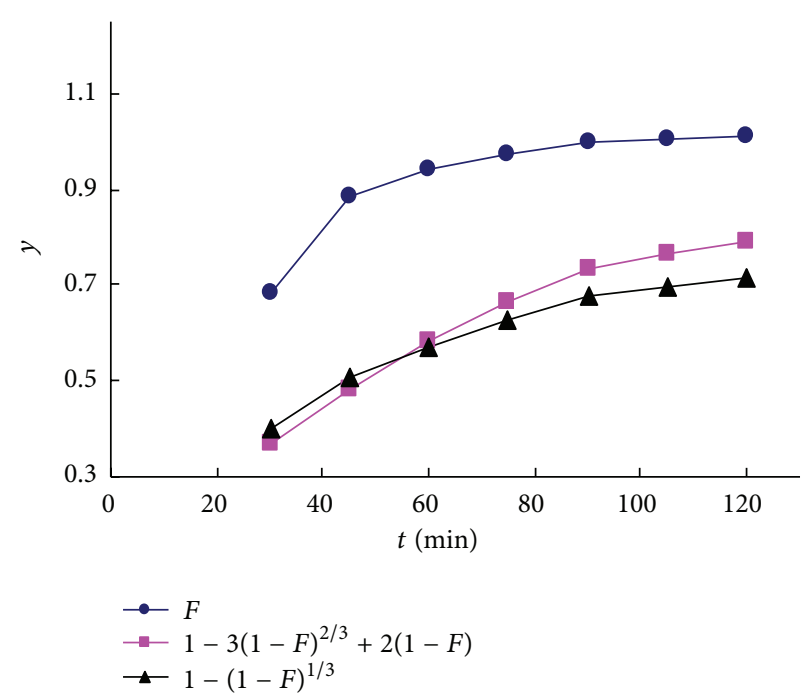

FIgURE 5: The fitting curve for the controlling step of kinetics.

TABLE 2: The reaction rate constants for $\mathrm{Ni}^{2+}$ adsorbed on $\mathrm{D} 301 \mathrm{R}$ resin.

Pseudo-first-order rate equation $\mathrm{HO}$-second-order rate equation

\begin{tabular}{lccccc}
$q_{e}(\mathrm{mg} / \mathrm{g})$ & $k_{1}$ & $r^{2}$ & $q_{e}(\mathrm{mg} / \mathrm{g})$ & $k_{2}$ & $r^{2}$ \\
\hline 69.39 & 0.03201 & 0.9813 & 86.20 & $9.9 \times 10^{-4}$ & 0.9675
\end{tabular}

3.2.2. Determination of Adsorption Rate Constants. The adsorption process is affected by the velocity of three steps $[15,16]$; they are the film diffusion (4), the particle diffusion, (5) and the chemical reaction (6). The step of which the speed is the slowest one controls the speed of the asorption, where $F$ is the exchange degree

$$
\begin{gathered}
F=k t, \\
1-3(1-F)^{2 / 3}+2(1-F)=k t, \\
1-(1-F)^{1 / 3}=k t .
\end{gathered}
$$

After the experimental data was processed with the equations, the results showed that both $1-3(1-F)^{2 / 3}+$ $2(1-F)$ and $1-(1-F)^{1 / 3}$ with respect to time had good linear (Figure 5). Their correlation coefficients were 0.9442 and 0.9287 . As the chemical reaction was quick and generally difficult to become the speed control step, the adsorption 
process of $\mathrm{Ni}(\mathrm{II})$ by $\mathrm{D} 301 \mathrm{R}$ resin can be initially identified to be controlled by the particle diffusion process. The rate constant $k$ was $4.7 \times 10^{-3} \mathrm{~s}^{-1}$, and it was shown the adsorption process was rapid.

3.2.3. The Effect of Ni(II) Concentration in Aqueous Solution on the Adsorption Kinetics. The effect of the initial concentration of $\mathrm{Ni}(\mathrm{II})$ in aqueous solution on the absorption kinetics was shown as Figure 6. It can be interpreted as: when the concentration of ions in aqueous solution was low and the exchange capacity of the resin was large, the mutual repulsive force between the same charges was greater. The ions in aqueous solution were not easy to enter the inside of particles of the resin and the rate of exchange process was slow. Appropriately increasing the concentration of $\mathrm{Ni}(\mathrm{II})$, the mutual exclusion between charges can be reduced. The probability of collision between molecules increased, and the reaction rate speeded up at last.

3.2.4. The Effect of $p H$ on Adsorption Kinetics. The uptake capacity of the resin was larger with being 8.0 (Figure 7). This may be due to changes of the ionic charges with respect to the changes of $\mathrm{pH}$ value. The adsorption properties on the ion exchange resin changed with the $\mathrm{pH}$ values of aqueous solution. Under mild alkaline medium, the charges on the resin were great, and the particle diffusion coefficient also increased with $\mathrm{pH}$ values being 8.0 in comparison with 6.0.

3.3. Infrared Spectra Analysis of the Adsorption Nickel by the Resin. According to principles of infrared spectrum, the infrared absorption frequencies of the group can be expressed as formula (9). Where $v$ is the adsorption frequency (wave number, $\mathrm{cm}^{-1}$ ), $k$ is a bond force constant, $u$ is the reduced mass of the group, and $C$ is the speed of light [16],

$$
v=\frac{1}{2 \pi C} \sqrt{\frac{k}{u}} .
$$

The decline of the bond force constants would directly lead to a decline in the infrared absorption frequencies of the groups. The stretching vibration frequency of $\mathrm{N}-\mathrm{H}$ was within $3500 \sim 3300 \mathrm{~cm}^{-1}$ (Figure 8 ). The bending vibration frequency of $\mathrm{N}-\mathrm{H}$ bond of the resin decreased from $1640.7 \mathrm{~cm}^{-1}$ unloading $\mathrm{Ni}(\mathrm{II})$ (Figure $8(\mathrm{a})$ ) to $1620.6 \mathrm{~cm}^{-1}$ loading $\mathrm{Ni}$ (II) (Figure 9(b)). There was a drop of $20.1 \mathrm{~cm}^{-1}$ for the bending vibration frequency of $\mathrm{N}-\mathrm{H}$. The change showed that the electron cloud distribution changed significantly on $\mathrm{N}-\mathrm{H}$ bond. Because of the forming of the coordination bond, the electron had more equal distributions on the original chemical bond, and the bond force constant $(k)$ decreased. The results showed that the coordination bond formed between nitrogen atom on the resin and nickel ion. There was the surface complexation in the adsorption of $\mathrm{Ni}$ (II) by D301R anion exchange resin through the infrared spectrum analysis.

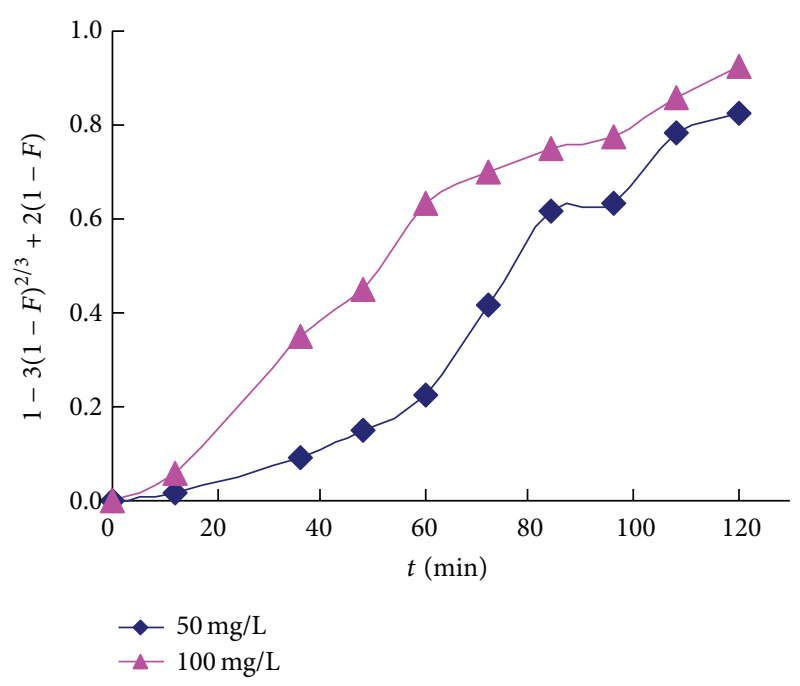

FIGURE 6: The fitting curves of the adsorption kinetics with different concentrations of solution.

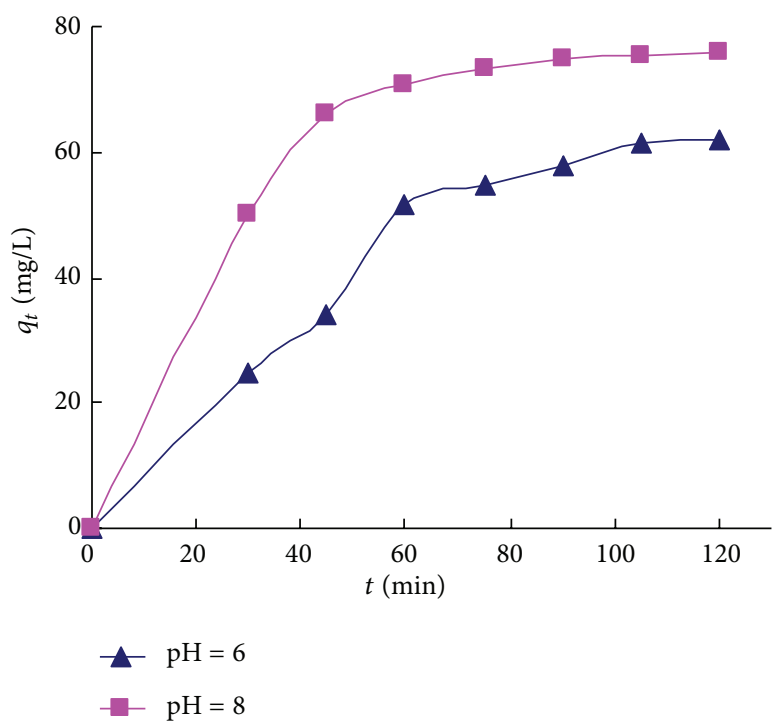

FIGURE 7: The effect of $\mathrm{pH}$ on the adsorption kinetics.

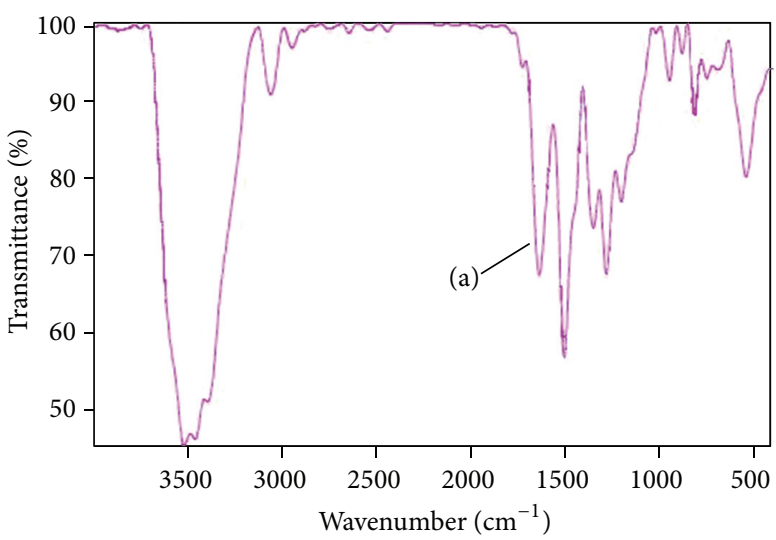

FIGURE 8: IR spectrum of D301R resin of unloading $\mathrm{Ni}^{2+}$. 


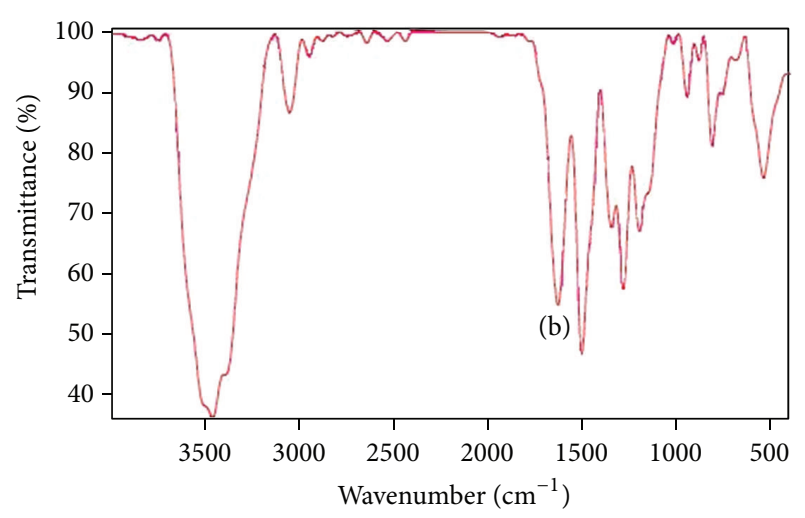

FIGURE 9: IR spectrum of D301R resin of loading $\mathrm{Ni}^{2+}$.

\section{Conclusions}

In the studied concentration range, the adsorption curve of $\mathrm{Ni}$ (II) by the D301R resin was better described by Langmuir isotherm model $\left(r^{2}=0.994\right)$ while that of $\mathrm{Ni}(\mathrm{II})$ sorption also fitted in Freundlich isotherm model. The Freundlich constant $(n)$ values were between 2 and 10; it was shown that the adsorption of $\mathrm{Ni}$ (II) on the resin is easy to take place. It was shown that adsorption process of $\mathrm{Ni}(\mathrm{II})$ on the resin fitted the first-order kinetic model $\left(r^{2}=0.9813\right)$ and the particle diffusion process was the speed control step. The diffusion coefficients increased when the $\mathrm{pH}$ values and the concentration of $\mathrm{Ni}$ (II) in aqueous solution also became larger. IR spectrum analysis showed that the bending vibration frequency of $\mathrm{N}-\mathrm{H}$ bond dropped by $20.1 \mathrm{~cm}^{-1}$ after adsorption of $\mathrm{Ni}$ (II) on the resin; the electron cloud distribution changed significantly on $\mathrm{N}-\mathrm{H}$ bond. The coordination bond formed between nitrogen atom on the resin and nickel ion. It was shown that the surface complexation did its work for the adsorption of $\mathrm{Ni}(\mathrm{II})$ by $\mathrm{D} 301 \mathrm{R}$ anion exchange resin.

\section{Conflict of Interests}

The authors declare that there is no conflict of interests regarding the publication of this paper.

\section{Acknowledgment}

The author Song Xiuling thanks her tutor (Mr. Qian) for giving the opinion in writing process.

\section{References}

[1] K. S. Kasprzak, F. W. Sunderman Jr., and K. Salnikow, "Nickel carcinogenesis," Mutation Research, vol. 533, no. 1-2, pp. 67-97, 2003.

[2] T. Norseth, "Cancer hazards caused by nickel and chromium exposure," Journal of Toxicology and Environmental Health, vol. 6, no. 5-6, pp. 1219-1227, 1980.

[3] S. Babel and T. A. Kurniawan, "Low-cost adsorbents for heavy metals uptake from contaminated water: a review," Journal of Hazardous Materials, vol. 97, no. 1-3, pp. 219-243, 2003.
[4] T. M. Ansari, K. Umbreen, R. Nadeem, and M. A. Hanif, "Polypogon monspeliensis waste biomass: a potential biosorbent for Cd II," African Journal of Biotechnology, vol. 8, no. 6, pp. 11361142, 2009.

[5] T. A. Kurniawan, G. Y. S. Chan, W. H. Lo, and S. Babel, "Physicochemical treatment techniques for wastewater laden with heavy metals," Chemical Engineering Journal, vol. 118, no. 1-2, pp. 8398, 2006

[6] M. N. Zafar, R. Nadeem, and M. A. Hanif, "Biosorption of nickel from protonated rice bran," Journal of Hazardous Materials, vol. 143, no. 1-2, pp. 478-485, 2007.

[7] R. Kiefer and W. H. Höll, "Sorption of heavy metals onto selective ion-exchange resins with aminophosphonate functional groups," Industrial and Engineering Chemistry Research, vol. 40, no. 21, pp. 4570-4576, 2001.

[8] W. H. Höll, J. Horst, and M. Franzreb, "Application of the surface complex formation model to exchange equilibria on ion exchange resins Part III: anion exchangers," Reactive Polymers, vol. 19, no. 1-2, pp. 123-136, 1993.

[9] W. H. Höll, "Elimination of heavy metal salts by adsorption onto weakly basic anion exchange resins," Vom Wasser, vol. 89, pp. 13-24, 1997.

[10] B. Benguella and H. Benaissa, "Cadmium removal from aqueous solutions by chitin: kinetic and equilibrium studies," Water Research, vol. 36, no. 10, pp. 2463-2474, 2002.

[11] A. Kausar, H. N. Bhatti, and G. Mackinnon, "Equilibrium, kinetic and thermodynamic studies on the removal of U(VI) by low cost agricultural waste," Colloids and Surfaces B, vol. 111, pp. 124-133, 2013.

[12] H. N. Bhatti and M. Amin, "Removal of zirconium(IV) from aqueous solution by Coriolus versicolor: equilibrium and thermodynamic study," Ecological Engineering, vol. 51, pp. 178-180, 2013.

[13] The National Environmental Protection Agency, Monitoring and Analysis of Water and Wastewater, Editorial Committee, Environmental Science Publishing House, Beijing, China, 4th edition, 2002 (Chinese).

[14] E. Metwally, "Kinetic studies for sorption of some metal ions from aqueous acid solutions onto TDA impregnated resin," Journal of Radioanalytical and Nuclear Chemistry, vol. 270, no. 3, pp. 559-566, 2006.

[15] G. D. Brykina, T. V. Marchak, L. S. Krysina, and T. A. Belyavskaya, "Sorption-photometric determination of copper by using AV-17 anion exchanger modified with 1-(2-thiazolylazo)-2-naphthol 3,6-disulphonic acid," Zhurnal Analiticheskoi Khimii, vol. 35, no. 12, pp. 2294-2299, 1980.

[16] V. Srihari and D. Ashutosh, "The kinetic and thermodynamic studies of phenol-sorption onto three agro-based carbons," Desalination, vol. 225, no. 1-3, pp. 220-234, 2008. 

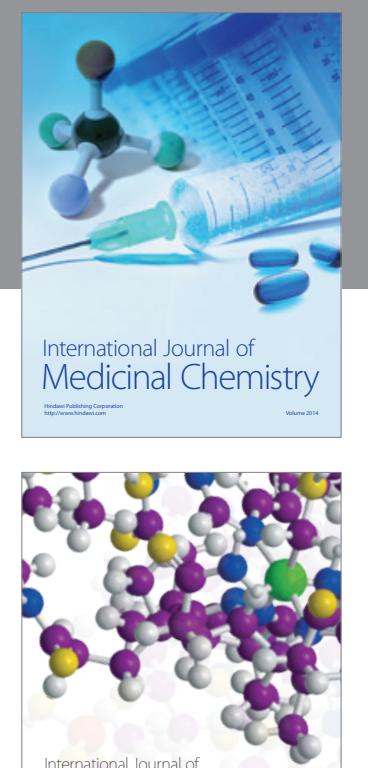

\section{Carbohydrate} Chemistry

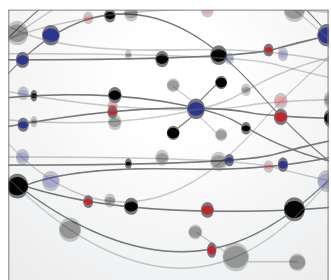

The Scientific World Journal
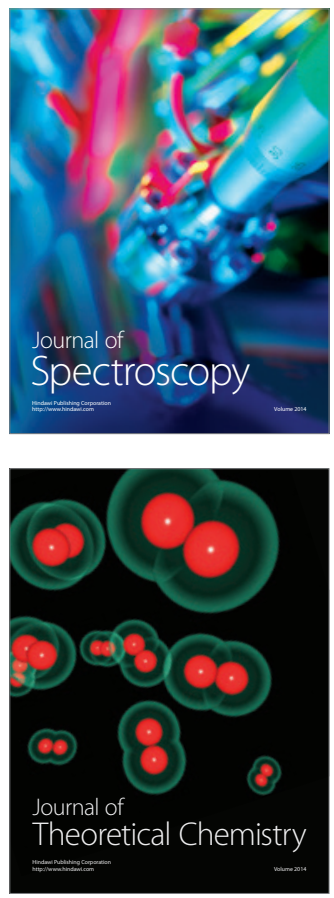
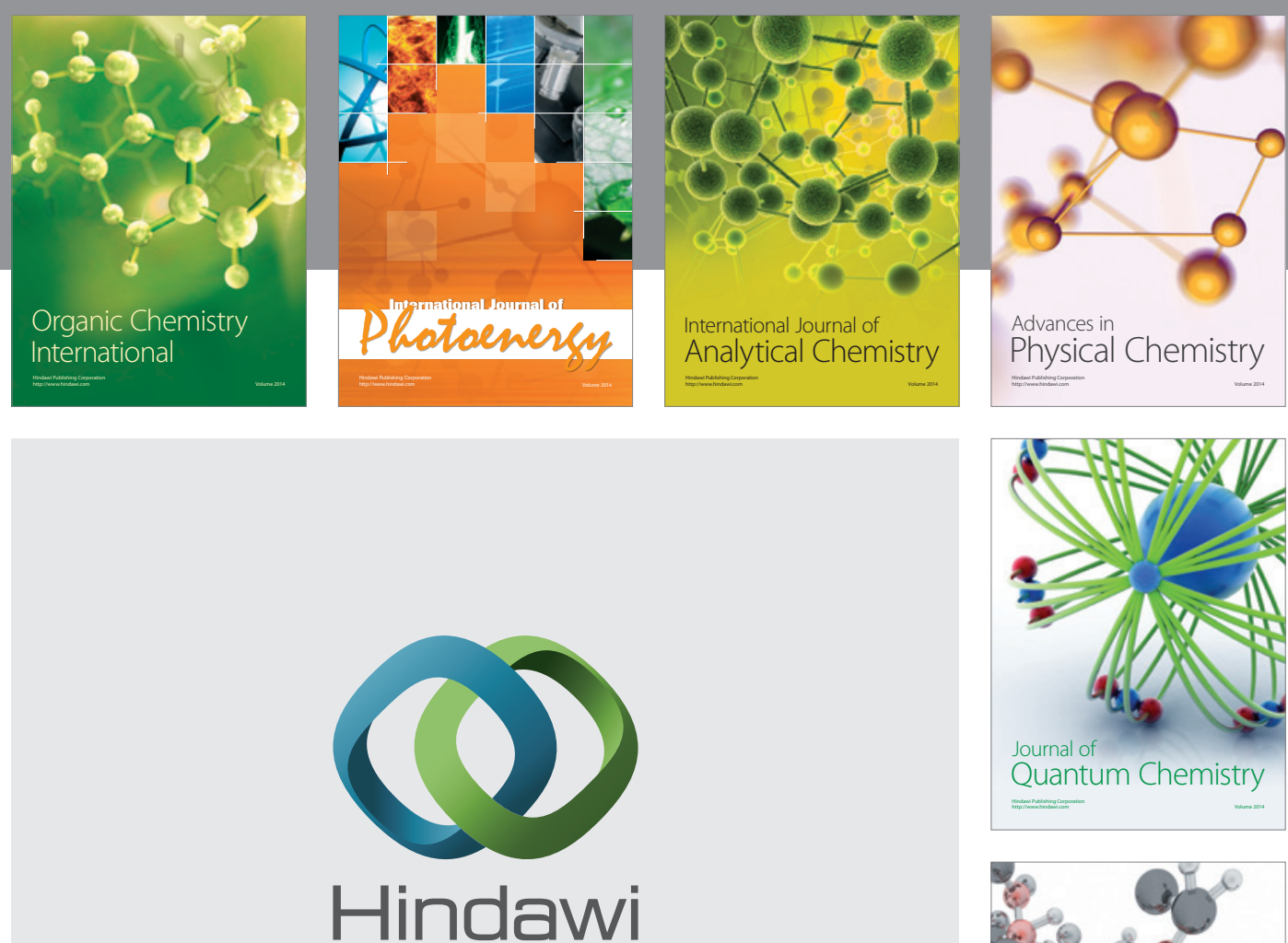

Submit your manuscripts at

http://www.hindawi.com

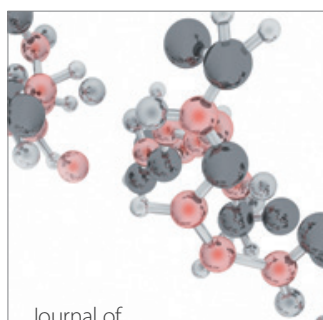

Analytical Methods

in Chemistry

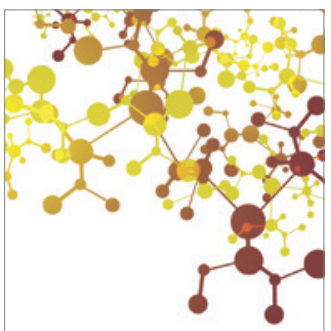

Journal of

Applied Chemistry

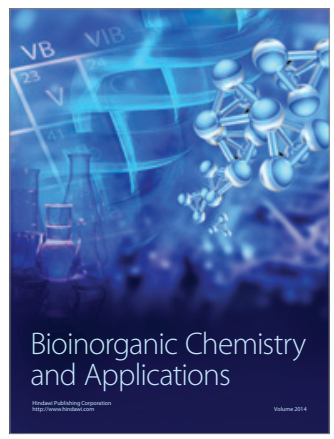

Inorganic Chemistry
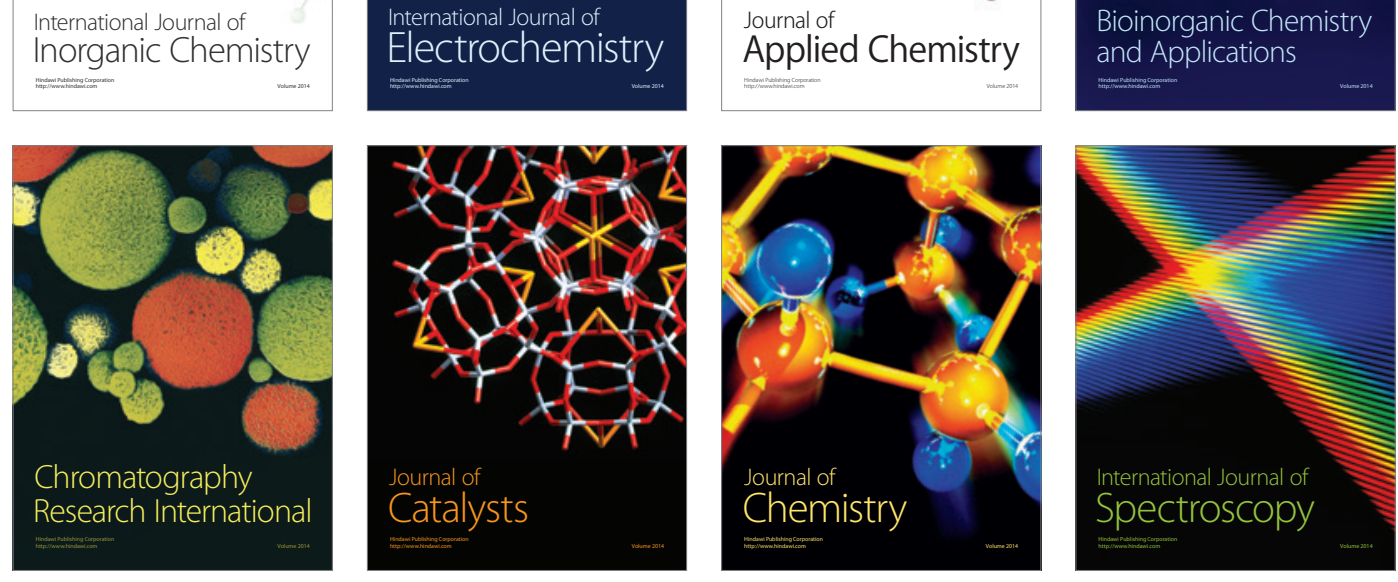